\title{
Trigemino Cardiac Reflex: A Finding in Skull Base Surgery That Could be Catastrophic- A Review of Literature
}

\author{
Eghosa Morgan*1,2, Obasi Okezie Kanu ${ }^{3}$, Babatunde Adetunmbi ${ }^{3}$ and Adeniji Adesida ${ }^{4}$ \\ ${ }^{1}$ Department of Surgery, Ambrose Alli University, Ekpoma \\ ${ }^{2}$ Department of Surgery, Irrua Specialist Teaching Hospital, Nigeria \\ ${ }^{3}$ Department of Surgery, Lagos University Teaching Hospital, Lagos \\ ${ }^{4}$ Department of Anesthesia, Lagos University Teaching Hospital, Lagos
}

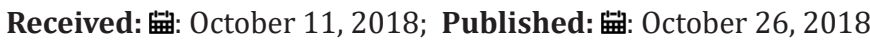

*Corresponding author: Eghosa Morgan, Department of Surgery, Ambrose Alli University, Nigeria

\section{Introduction}

Skull base surgery is an integral part of neurosurgical endeavor, the presence of vital neural structures located there as well as exit/ entry foramina for cranial nerves and blood vessels poses a great challenge to the neurosurgeon who must do all possible to preserve this structures during neurosurgical intervention and as well as the neuroanaesthetist who had to continuously monitored neurovital signs which guide the surgeon in view of structure such as the brainstem which controls cardiorespiratory activities located in the skull base. These vital structures regulate the dynamic body reflexes (cardiorespiratory center) and cranial nerves important for control of body function. The trigeminal nerve, which is the largest cranial nerve with mainly sensory supply to the craniofacial structure is involved in the trigeminocardiac reflex. Trigeminocardiac reflex is a well know entity consisting of bradycardia, arterial hypotension, apnea and gastric hypermotility [1]. In skull base surgeries, awareness of a rapid drop in pulse rate, mean arterial pressure more than $20 \%$ of baseline values following stimulation of the peripheral or central branches of trigeminal nerves or the structure it supplies should be recognized [1-3] and could avert calamity during neurosurgical intervention.

\section{Literature Review}

Trigemino-cardiac Reflex [TCR] is defined as sudden drop in heart rate, mean arterial pressure of $20 \%$ or more compared with baseline values before stimulation and coinciding with manipulation of trigeminal nerve [peripheral or central] or structures supply by it excluding pathological contributions. TCR occur with a frequency of $8-18 \%$ in adult patient during different surgical procedure involving the skull base [2-4]. It is not a pathological event, but can be a neuroprotective phenomenon [5] in calling for attention to prevent or combat it, thereby preventing far reaching consequences on the patient. Despite triumph in micro neurosurgical technique by Yasargil in the 1960s, occurrence of TCR is traced to structural changes in brainstem [6]. TCR has evolved over time, first described in 1870 by Kratchner, Kumada et al [7] until recently when Schaller popularized it [2]. Several surgical procedures involving the craniofacial areas, skull base, percutaneous procedure related to trigeminal nerve have been found to be associated with bradycardia, arterial hypotension and asystole with far reaching devastating sequelae [8-12]

Manipulation at or near the trigeminal nerve distribution or structures that it supplies has been traced as a cause of TCR [13]. Mechanism of TCR is poorly understood and elusive, but current theoretical bases is a reflex manipulation of trigeminal nerve at different level or structures that are innervated by this nerve [14]. It may induce neuronal signal to sensory trigeminal nucleus through the gasserian ganglion which constitute an afferent pathway of their reflex arc [14]. Others have suggested that afferent impulses are transmitted to the peripheral sensory nucleus of the trigeminal nerve and spinal nucleus of trigeminal nerve [14]. The sensory nuclei connect with the autonomic vagal motor nucleus by through short internuncial fibre to the vagal motor nucleus of the medulla [14]. The vagal parasympathetic nerve fibre cell bodies with descending cardiac fibers are located within the dorsal motor 
nucleus of the vagus and the nucleus ambiguous, from where cardioinhibitory fibers arises and terminate in the myocardium causing bradycardia, asystole and rarely arrthymia. Oculocardiac reflex (a variant of TCR) is induced by mechanical stimulation of ocular and periocular structure innervated by CNV1, is elicited by stimulation of the afferent pathway of the long ciliary nerve (CNV2), submucosa of the nose by nasociliary branch of CNV1, sensory branch of CNV2 OR V3 $[15,16]$.

Premedication with Anticholinergic drugs [such as atropine] can lead to cessation of irritation from surgical manipulation so as to disrupt the reflex that trigger the response [13]. Appropriate selection of Anticholinergic is needed in cases in which manipulation of the cavernous sinus is inevitable. Glycopyrrolate has been found to be has been found to be superior to atropine in managing TCR in view of central anticholinergic syndrome of atropine as it crosses blood brain barrier [17]. Atropine has been found to be effective in treating refractory TCR, while glycopyrrolate is considered for prevention during further surgical manipulation of the trigeminal nerve or structure it supply or with pacemaker on insertion [11,17]. Defining a clear-cut determinant for those patients with greater risk of TCR following Skull Base Surgery (Transsphenoidal Surgery) has been elusive. No correlation of age, sex, tumor history, method of anesthesia, duration and distribution of clinical symptoms have been traced to TCR. Reports have shown that important determining factor is cavernous sinus thrombosis manipulation. Another predicting factor of the doubtful acceptance is intravenous anesthesia surfactants potentiating TCR [18], but now clear evidence has been found.

Management of TRC involved early detection of bradycardia and or hypotension with continuous monitoring of hemodynamic stability, stoppage of all surgical manipulation. In the work by Koerbel et al, $80 \%$ of the patient had TCR during Skull Base Surgery hemodynamic parameters return to normal within 20 seconds of stopping surgical stimulation Atropine has been found useful in preventing recurrence of the reflex [19].

\section{Conclusion}

TCR should be discussed with all team members including the anesthetists involved in Skull Base Surgery in view of preparation for identification. Every skull base surgeon should be aware of the occurrence of TCR and strive to prevent it or treat it when it occurs with available pharmacological agents.

\section{References}

1. Seker A, Toktas ZO, Peker S, Halit Abbas Batirel (2009) Asystole due to Trigemino cardiac reflex. A rare complication of transsphenoidal surgery for pituitary adenoma. J Clin Neurosci 16: 338-340.
2. Schaller B, piobst R, Strebel, Gratzl O (1999) Trigemino cardiac reflex during surgery in the cerebellopontine angle. J Neurosurgery $90(2)$ : 215-220.

3. Schaller B (2005) Trigeminocardiac reflex during transsphenoidal surgery for pituitary adenoma. Clin Neuro/Neurosurg 107(6): 468-474.

4. Schaller B (2005) Trigemino Cardiac reflex during microvascular trigeminal decompression in cases of trigeminal neuralgia J. Neurosurg Anesthesiology 17(1): 45-48.

5. Schaller B (2004) Trigeminocardiac reflex; A clinical phenomenon or a new physiological entity? J Neurol 251(6): 658-665.

6. Schaller B, Sandu N, Filis A, J Rasper, C Noethen (2008) Trigeminocardiac reflex may be refractory to conventional management in Adult Acta neuroclin (Wen) 150: 929-930.

7. Kumada M, Dampney RA, Reis DJ (1975) Trigeminal depressor response, a cardiovascular reflex originating from the trigeminal system. Brain Res 92(3): 485-489.

8. Kapour W, Jannelta P (1984) Trigeminal Neuralgia associated with seizure and syncope. J Neurosurg 61(3): 594-595.

9. Lang S, Larigan D, Ven Der Wal M (1991) Trigeminocardiac reflex, Maxillary and Mandibular Variants of the oculocardiac reflex. Can J Anaesth 38(6): 757-760.

10. Loewinger J, Cohen M, Levi E (1987) Bradycardia during elevation of a Zygomatic arc fracture J oral Maxillosacr Surg 45(8): 710-711.

11. Ragno J, Marcoot R, Tyler S (1989) Asystolic during Le Forte1 Osreomy. J Oral Maxillosac Surg 47(10): 1082-1083.

12. Spaziante R, Cappabianca P, Peca C (1985) subarachnoid hemorrhage and normal pressure hydrocephalus; Fetal Complications of Percutaneous icro decompression of the gasserian ganglion. Case report Neurosurgery 22: 148-151.

13. Angel James JE, Daly MB (1969) Nasal reflex Pwc Roy Soc Med 62: 12871293

14. Barnard RA, Bainton R (1990) Bradycardia and the trigerminal nerve J Crani. Maxillofac Surgery 18(8): 359-360.

15. Angel James, Daly MB (1975) Some aspect of upper respiratory tract reflexes Acta Otolaryngol 79(3-4): 242-252.

16. Beith OB (1996) Problems of anesthesia in strabismus Surgery. Int Ophthalmol Clin 6(3): 727-737.

17. Hunsley J, Bush G, Jones C (1982) A study of glycopyrolate and atropine in suppression of oculocardiac reflex during strabismus surgery in children Br. J Anaesth 54(4): 459-464.

18. Alton R, Wright T (1990) Possible potentiation of trigerminocardiac response by Sufentanil J Oral Maxillosac Surg 48: 770.

19. Schaller B, Buchfelder M (2006) Trigerminocardiac reflex. A recently diagnosed oxygen conserving "response" The potential role of a physiologic reflex Arch Med Sci 2: 3-5. 


\section{ISSN: 2574-1241}

DOI: 10.26717/BJSTR.2018.10.001954

Eghosa Morgan. Biomed J Sci \& Tech Res

(c) (P) This work is licensed under Creative

Submission Link: https://biomedres.us/submit-manuscript.php

$\begin{array}{ll}\text { BIOMEDICAL } & \text { Assets of Publishing with us } \\ \text { RESEARCHES } & \text { - Global archiving of articles } \\ \text { - Immediate, unrestricted online access } \\ \text { https://biomedres.us/ }\end{array}$

